\title{
Evaluation of the Effect of Probiotics Isolated from Traditional Dairy Products on the Expression of Stx 1 and Stx2 Genes of Verotoxigenic Escherichia coli (VTEC) in Laboratory Conditions
}

\author{
Changiz Ahmadizadeh, ${ }^{1, *}$ and Hamid Mirzaei ${ }^{2}$ \\ ${ }^{1}$ Department of Biology Ahar Branch, Islamic Azad University, Ahar, Iran \\ ${ }^{2}$ Department of food hygiene, Tabriz Branch, Islamic Azad University, Tabriz, Iran \\ "Corresponding author: Changiz Ahmadizadeh, Assistant Professor in Microbiology, Department of Biology Ahar Branch, Islamic Azad University, Ahar, Iran. Tel: \\ +98-9104030464, E-mail: dr_ahmadizadeh@yahoo.com
}

Received 2017 November 01; Revised 2017 December 26; Accepted 2018 January 23.

\begin{abstract}
Background: Lactobacilli are commonly used organisms in the production of probiotics.

Objectives: The present study was conducted to examine the effect of probiotics isolated from dairy products on the expression of Stx1 and Stx2 genes in verotoxigenic E. coli (VTEC).

Methods: This experimental study was conducted during April and January 2016 in East Azerbaijan, Iran. At first, Hundred samples of traditional dairy products were collected. Then, using standard phenotypic and genotypic methods, the Lactobacillus casei (L. casei) and lactobacillus (L. plantarum) were studied. Subsequently, these strains were examined along with the pathogenic bacteria strain of Escherichia coli (E. coli) (O157: H7) by neighboring cultivation. After extraction of mRNA, the expression of these genes was determined using real- time PCR.

Results: The results revealed that $L$. casei reduces the expression of Shiga toxin (Stx1 and Stx2) genes more compared to L. plantarum $(\mathrm{P}=0.001)$. Moreover, it was found that both Lactobacilli reduce the expression of Stx1 genes more than Stx2.

Conclusions: Probiotics could be used to prevent and control intestinal diseases caused by E. coli.
\end{abstract}

Keywords: Escherichia coli, Expression, Gene, Probiotic, Shiga toxin, Stx1, Stx2, Verotoxigenic

\section{Background}

Probiotics, including Lactobacillus species, are viable and beneficial microorganisms that can be used in humans or animals; they have an effect on the microbial flora of the body, leading to beneficial effects on the host health (1-4). Many studies have indicated that probiotics are important in preventing and curing intestinal disorders, such as diarrhea and pouchitis. Most probiotics belong to a large group of the microbial flora of humans' intestines and some of these microorganisms are strains of Lactobacillus bacteria that are rarely pathogenic to humans and animals (5). Lactobacillus is polymorphic, anaerobic, and nonmotile bacterium, and generates energy by fermentation of sugars $(6,7)$. The beneficial effects of probiotics on host protection, especially against digestive tract disease, are performed by inhibitor compounds such as organic acids (acetate), propionate butyrate, $\mathrm{H} 2 \mathrm{O} 2$, and bacteriocin compounds. Among these compounds, bacteriocin with the most effective inhibitory activity against bacterial species has been most commonly studied (8). Lactobacillus commonly exists in yogurt and other dairy products that enhance the immune system, improve the intesti- nal absorption and digestion, eliminate pathogenic bacteria, prevent the binding of these agents to the intestinal wall, and compete with the pathogen $(9,10)$.

Among the available strains, at least 100 serotypes of E. coli are capable of producing Vero toxin. However, among these serotypes, E. coli $\mathrm{O} 157$ : $\mathrm{H} 7 \mathrm{in}$ humans is known as EHEC. O157: H7 strain is one of the most important causes of intestinal infections (11). This bacterium produces severe bloody diarrhea and high-risk diseases, such as hemolytic uremic syndrome (HUS), hemorrhagic colitis (HC), and thrombotic thrombocytopenic purpura (TTP) $(12,13)$. This bacterium is known as one of the food-borne pathogens. Shiga toxin- producing E. coli (STEC) can survive for a long time in such foods as apples, sausages, and mayonnaise. One of the other abilities of this bacterium is the lower infectious dose (less than 100), and therefore all enterohemorrhagic E. coli strains observed in animals are considered as risk factors for humans. However, the O157 serotype can cause disease in humans $(14,15)$. E. coli pathogenicity factors: H7 O157, such as toxins, adhesin, hemolysin, lipopolysaccharide, and flagellum play a significant role in low levels of infectious doses of this bac-

Copyright (c) 2018, Iranian Red Crescent Medical Journal. This is an open-access article distributed under the terms of the Creative Commons Attribution-NonCommercial 4.0 International License (http://creativecommons.org/licenses/by-nc/4.0/) which permits copy and redistribute the material just in noncommercial usages, provided the original work is properly cited 
terium (16). Also, E. coli strains can disturb the integrity of cytoskeleton and cell-cell tight junction in host epithelial cells. Shiga toxin $1 \& 2$ (Stx-1 and Stx2) are the most critical toxins produced by this bacterium (17). Shiga toxin and lipopolysaccharide are also the essential factors in the creation of HUS (13). It is also called Vero toxin because of the lethal effects of the toxin in the Vero cell line from African green monkey kidney (12). The consumption of antibiotics to treat and prevent infections caused by this bacterium not only produces drug resistance but also interferes with the normal digestive tract flora, making the body susceptible to a variety of intestinal diseases. On the other hand, the use of antibiotics in treatment causes the phage Stx carriers to pass the circulatory cycle (lytic) and increases the secretion of Stx and the progression of the disease to HUS in the antibiotics recipient (18-20). Thus, in this study, we determined the effect of lactobacilli isolated from dairy products on the expression of Stx1 and Stx2 genes that involved in the pathogenesis of VTEC. Also, we conducted this study taking into account the following factors: the importance of this bacterium in acute illness; low infectious doses; and the presence of various pathogenic agents, such as the production of toxins and their transfer by food. In conducting this study, we also considered that previous studies have indicated that probiotics play a significant role in the prevention of intestinal diseases.

\section{Methods}

\subsection{Sample Collection}

This experimental study was performed in East Azerbaijan province, Iran, from during April 2016 to January 2016. Samples were collected from local dairy products (yogurt and cheese) in the villages around city of Ahar in East Azerbaijan province, Iran. With the population of 3.725 million, East Azerbaijan province is diverse in climate, and its economy depends on large industries and agricultural and commercial activities. The number of examined samples was large enough, so that at least one isolate could be studied from each of the probiotics.

\subsection{Cell Cultures}

Sampling was based on Morgan formula, which was calculated to be 100 samples. Samples of dairy products were collected in sterile conditions and transferred in sterile containers (Falcon $50 \mathrm{ml}$ ) to the laboratory in the vicinity of ice. First, we ensured that equipment was calibrated. Then, bacterial suspension was prepared by Kalycha and its associated method using PPS solution and primary culture of bacteria in MRS liquid culture medium (Micro media). Next, bacterial cultures were transferred to the PBS medium with $\mathrm{pH} 2.5$ ( $\mathrm{pH}$ meter -Met Rohm-Sweden) to be isolated based on Erkila Pnajah method; isolates were resistant to Acid. After determining the survival percentage of isolates in the acidic medium, the resistance of the isolates to bile salts was determined using Gil Liland et al. method in a liquid MRS medium with $0.3 \%$ Oxall (Merck). Spectrophotometric apparatus every half an hour recorded growth in control and treatment cultures by measuring the absorbance at $600 \mathrm{~nm}$ wavelength using spectrophotometer (Pharmacia-Biotech-England). The absorption curve was plotted based on incubation time. After identifying the probiotic potential of isolated strains based on the proposed method in the Barji and Asnes book in 1986 and Wood and Holzappel in 1995, the phenotypic isolates were identified using catalase test, gram coloring, growth at temperatures, and different $\mathrm{pH}$, and tolerance to the concentration of different salts.

\subsection{Study of Gene Expression}

The next step was to identify acid-base and Beyle resistant strains using SrRNA molecular methods and sequencing. PCR reaction was performed using specific primers, such that DNA was extracted from all isolates using the C-TAB method reported in the sources or using the DNA extraction DNPTM kit (High yield DNA purification- Sinacolon, Iran). One percent agarose (Invitrogen-USA) gel for electrophoresis was used to evaluate the qualification of the extracted DNA. Specific primers for the propagation of 16SrRNA fragments for Lactobacillus strains were designed using oligo7 software and blast with 16S rDNA sequences found on the NCBI GeneBank site.

After selecting probiotic potential strains, the antibacterial effect of these strains on the $0157 \mathrm{H} 7$ bacilli were performed using a disc diffusion method with a 24-hour filtered medium of selected lactobacilli. Bacteria with antibacterial effects cannot be used to study the effects on the expression of the enterotoxin gene of E. coli, as these bacteria will be extinct after exposure to bacteriocins, and gene expression will stop. However, one example of bacteriocin lactobacilli can be used as a negative control. Finally, the effect of four bacteria of Lactobacillus of different species with probiotic potential and two standard strains of plantarum and casei, which are available in the market as probiotic pills, were investigated using neighboring cultures along with coli 0157 strain bacteria. Inclusion criteria were based on Lactobacillus phenotypic characteristics and resistance to bile salts. The bacteria that were not resistance to bile salts and did not have Lactobacillus - related genotypic and phenotypic characteristics were excluded from this study. The presence of Stx 1 and Stx 2 genes for the mentioned strains was confirmed using PCR. Neighboring cultures of O157: H7 and O57: H7 VTEC with probiotic bacte- 
ria was done in the near term after 1,4 , and 8 hours. Then, RNA was extracted from adjacent bacteria using RNA extraction kit (Mini-Preps Kit-Canada), according to the protocol of the company. The quantitative and quantitative information of the extracted RNA was evaluated by nanodrop instrument (NanoDrop ND-1000 spectrophotometer). Initial inoculation of both bacteria and probiotics with opacity was $\mathrm{OD}=0.5$, both bacteria were in the logarithmic phase of growth. After extracting RNA using synthetic kit of cDNA, cDNA was prepared from RNA. About 1 $\mu \mathrm{g}$ of RNA was converted to cDNA by the Rovers transcript enzyme of the MMLV (Takara, Japan), at the temperature of $42^{\circ} \mathrm{C}$ for one hour using thermocycler (Takara -Japan). The obtained cDNA was kept in the refrigerator-70 (BoschGermany) until quantitative PCR was performed. For realtime PCR experiments, primer was designed for Stx1 and Stx2 genes and sent to a German company (MWG) or another company for synthesis. In addition, by designing a primer pair for the 16srRNA gene, this gene was used as a control, as a data normalizer in quantitative PCR, and as a housekeeping gene. Quantitative PCR was done by CyberGreens method and QuantiTect SYBR Green PCR kit. Four local probiotic bacteria with two standard probiotic bacterial isolates from probiotic pills in the medicine market (six probiotic bacteria and two strains of pathogenic bacteria) were used as positive control and in triplet. The standard diagram was drawn using five - times cDNA dilutions of a positive affinity with factor 10 . Specificity control of reproduction was performed by plotting the melting curve. The obtained data were analyzed using the Delta-Delta-Ct formula $(\Delta \Delta \mathrm{CT})$ proposed by pfaffl in 2001 and by Rest program.

\subsection{Statistical Methods}

Data were analyzed using SPSS software, Version 20 (IBM Corp., Armonk, N.Y., USA). The results that showed a normal distribution were compared using one-way ANOVA, and the results that were not normally distributed were compared by Mann- Whitney U non-parametric test $(\mathrm{P}<0.05)$.

\section{Results}

Isolates of the strains of L. casei and plantarum of dairy products, such as yogurt and cheese, were randomly selected from the villages around city of Ahar, Iran. It was assured that there were no commercial strains and sterile conditions in this area. Then, using standard phenotypic methods, such as isolating acid resistant strains and determining their resistance to acid and determining the tolerance of isolates to bile salts, lactobacilli phenotypes were identified.

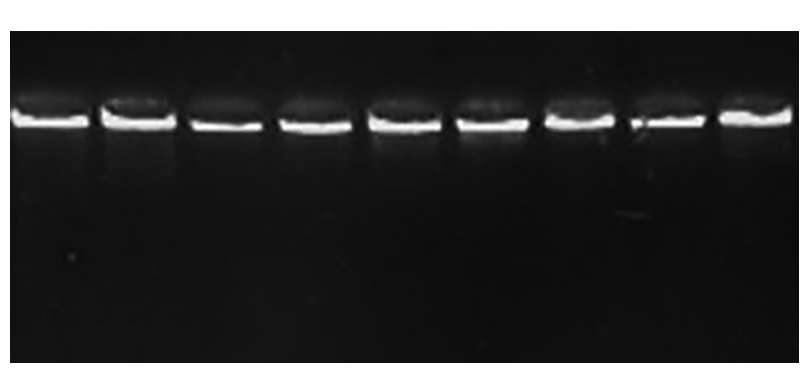

Figure 1. Electrophoresis of DNA extraction from isolated strains

\subsection{DNA Extraction}

After extraction of DNA from isolated bacteria, about $5 \mu \mathrm{L}$ of extracted DNA in $0.8 \%$ agarose gel was loaded. After performing electrophoresis for one hour at a voltage of 100 volts, the quality of the bands was studied under UV rays. Then, samples of DNAs with good bands quality were selected. Figure1 demonstrates the DNA extraction sample.

\subsection{Reproduction of Lactobacillus Isolates of 16s rRNA Se-} quences

Sequences of $16 \mathrm{~s}$ rRNA isolates were amplified using a pair of primers designed during polymerase chain reaction (Figure 2).

As seen in the proliferation proliferation products were obtained at approximately 1500 pairs of nucleotides and as a single strip. The 1 - kb DNA Ladder was used to represent the size of the plots. The electrophoresis of the amplified products in agarose gel was $1.5 \%$.

In the present study, Stx1 and Stx2 specific primers were used as internal controls using SYBR GREEN and 16S rDNA genes. In Muller Hinton medium, the bacteria of $L$. caesi and plantarum with E. coli (from each bacterium with OD $=0.5 \mathrm{cc}$ ) were incubated for 1,4 , and 8 hours at $37^{\circ} \mathrm{C}$. After centrifugation of the bacteria, RNA was extracted using thrysol. After nanodrop and determining the amount of RNA, cDNA synthesis was performed. Results revealed that lactobacilli caesi and plantarum affect the expression of Shigotoxin and can affect the virulence of the E. coli bacterium and decrease its growth. In addition, results showed that $L$. caesi reduced the amount of gene expression in comparison to plantarum. The results of culture revealed that in four hours cultivation, the gene expression in both bacteria decreased more than 8 hours. It is likely that as the time passes, the effects of $L$. cysine and plantarum on the E. coli are reduced. Also, the results indicated that both lactobacilli reduced the expression of Stx1 gene more than Stx2, and there was not a significant difference between them $(\mathrm{P}<001)$. 


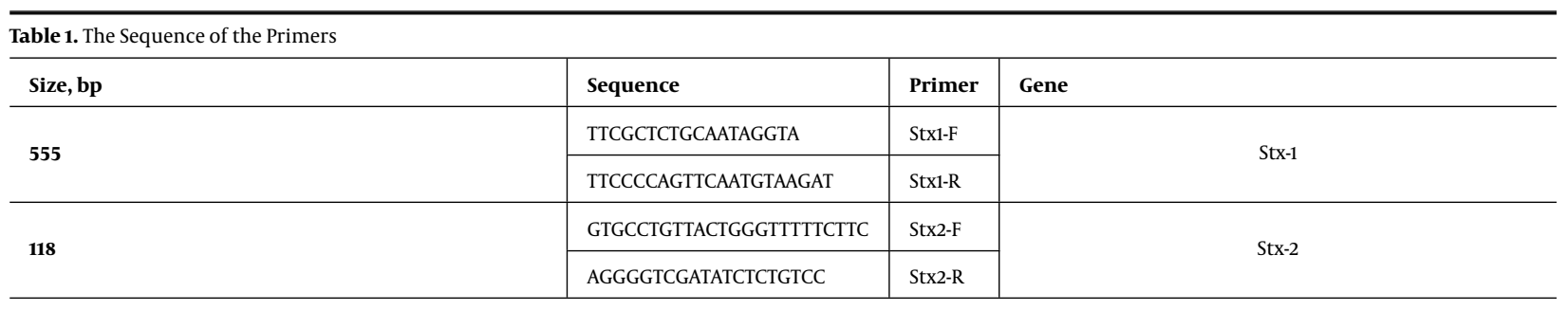

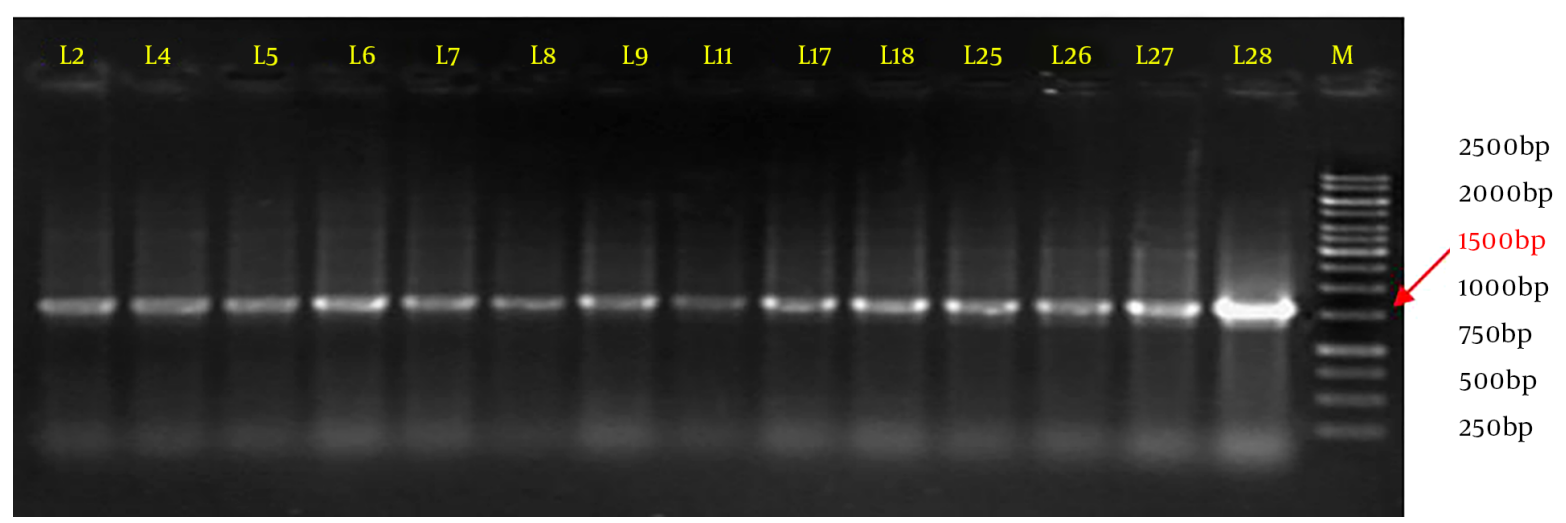

Figure 2. Electrophoresis of proliferation products of $16 \mathrm{~s}$ rRNA sequences for Lactobacillus isolates strains

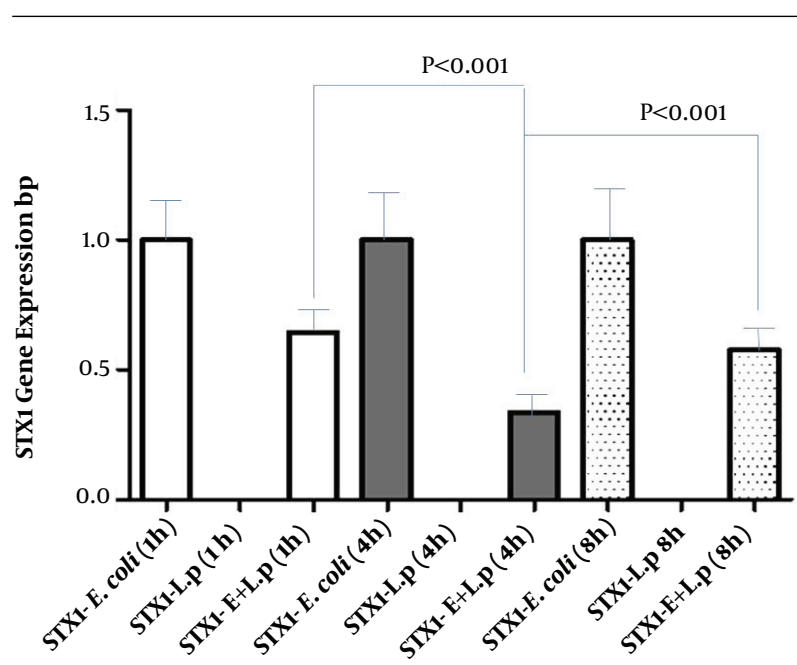

Figure 3. Effect of L.plantarum on the expression of Stx1 gene in real- time PCR results (results were reported as a median based on non-parametric and one-way ANOVA tests using SPSS, Version 20.)

\section{Discussion}

This study showed that cheese and yogurt produced by traditional methods are an important source for probiotic bacteria. After isolation and identification of casei and plantarum lactobacilli, the effect of these bacteria on the expression of Stx1 and Stx2 genes was studied. Many

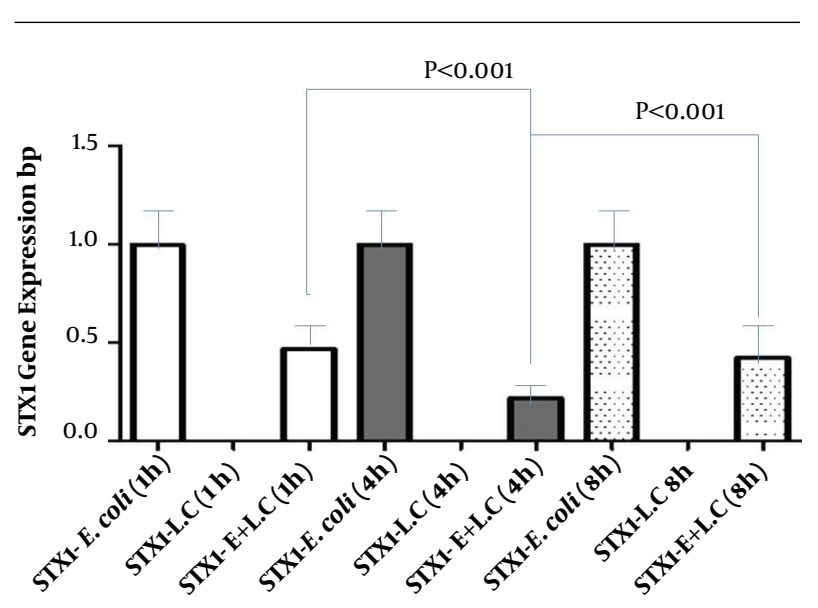

Figure 4. Effect of $L$. casei on the expression of Stx1 gene in real- time PCR results (results were reported as a median based on non-parametric and one-way ANOVA tests using SPSS, Version 20)

studies have been conducted on probiotic species of Lactobacillus and their effects on pathogenic bacteria, such as E. coli in dairy products; and they have indicated that these bacteria can reduce the growth of E. coli. However, to date, no studies have been conducted on casei and plantarum species. The present study found that $L$. casei reduces the amount of gene expression more than plantarum. The results of culture showed that in 4 hours cultivation, the 


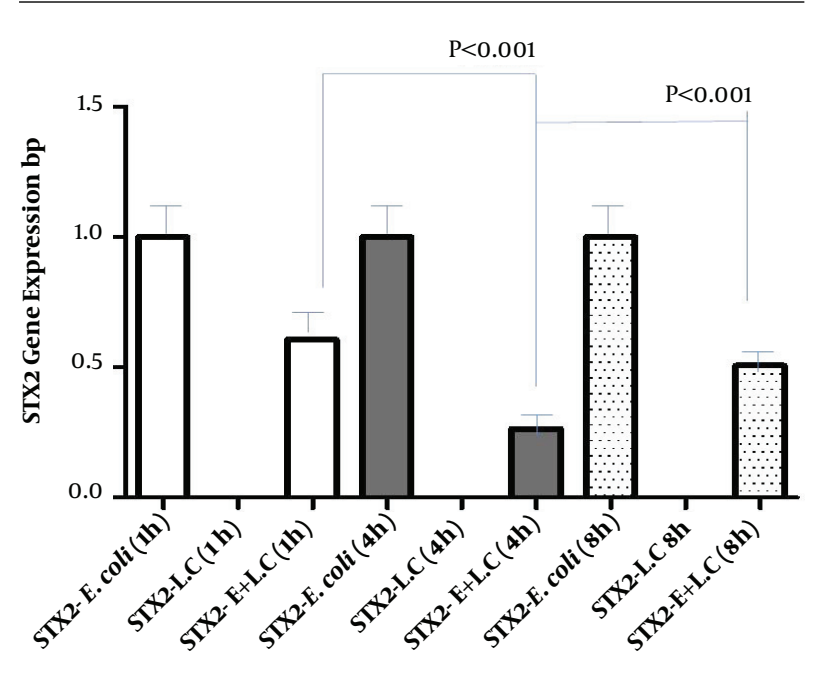

Figure 5. Effect of $L$. casei on the expression of Stx2 gene in real- time PCR results (results were reported as a median based on non-parametric and one-way ANOVA tests using SPSS, Version 20)

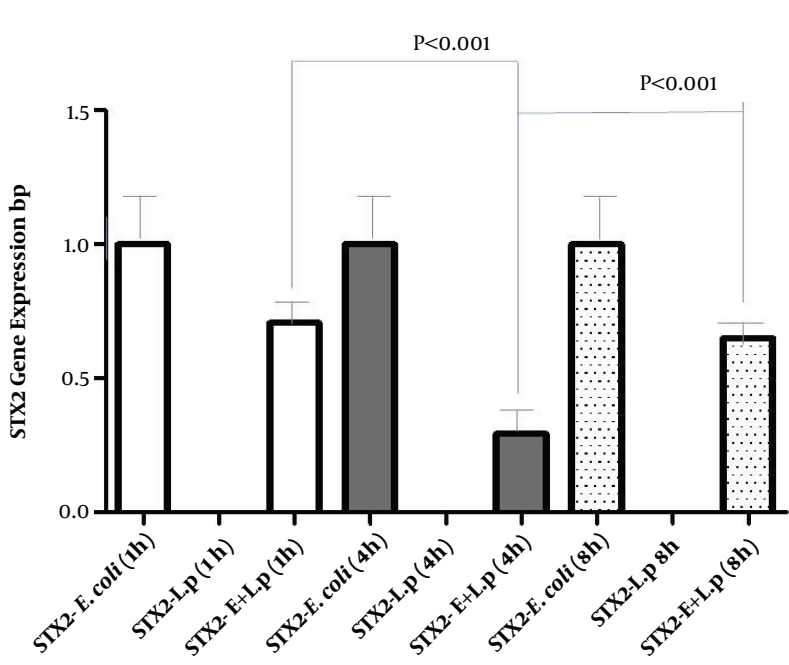

Figure 6. Effect of L. plantarum on the expression of Stx2 gene in real- time PCR results (results were reported as a median based on non-parametric and one-way ANOVA tests using SPSS, Version 20)

gene expression in both bacteria decreased more than 8 hours. It is likely that with the passage of time, the effects of L. casei and plantarum on the E. coli are reduced. The results also indicated that both Lactobacilli reduced the expression of Stx1 gene more than Stx2. Silva et al. (21) demonstrated that L. rhamnosus GG has anti-bactericidal effects against a variety of pathogens strains, such as Pseudomonas, Salmonella, Clostridium, and E. coli B-44. Also, other studies showed that L. plantarum exerted a beneficial effect against the damage to integrity of Caco-2 monolayer cells, which was previously infected by Enteroinva- sive Escherichia coli (EIEC) infection (22). However, it can be concluded that $L$. casei is superior to the plantarum strain on the growth of the E. coli bacteria. In this study, due to the importance of Enterohemorrhagic E. coli (EHEC) pathogenesis strains O157: H7, the inhibitory effect of Lactobacillus on the expression of Stx-2 and Stx-1 gene was evaluated. By examining the effect of Escherichia coli O157: H7 strains with different genes in laboratory and intracellular conditions, many scientists have shown that strains of Stx-2 gene compared to Stx-1 gene strains or both Stx-1 and $S t x-2$ genes are more pathogenic. Their finding was also confirmed by our results. Ogunbanw et al. investigated antimicrobial activity and the production of bacteriosins by Lactobacillus in 2003. The researchers, using the wells method, showed that Lactobacillus inhibits the growth of E. coli, Bacillus cereus (B. cereus), and Yersinia enterocolitica (23). Wolf et al. in 2000, using the wells method showed that the fermented milk mixture containing $L$. casei inhibited the growth of intestinal pathogens including Shigella dysentery, Salmonella typhimurium (S. typhimurium), and E. coli (24). With respect to the antibacterial effect, lactobacillus produces non-bacteriocidic substances that are unknown and different from lactic acid. Also, it extensively inhibits the growth of Gram- positive and negative pathogens, such as Staphylococcus aureus (S. aureus), Listeria monocytogenes (L. monocytogenes), (S. typhimurium), Shigella Flexneri (S. Flexneri), Klebsiella pneumonia, Pseudomonas aeruginosa (P. aeruginosa), and Bacteria. In 2003, in a laboratory experiment, Lee et al. found that L. casei strain of Shirota, in competition with gastrointestinal bacteria, prevented binding to the Caco-2 cell line about $46 \%$. In this study, it was determined that the highest inhibition of L. casei Shirota (Above 30\%) is on E. coli TGI (S. typhimurium), E10, E. coli ATCC1775, and (S. typhimurium) ATCC14028 (25). In 2003, Laura introduced the mechanism of inhibitory effect of Lactobacillus and Bifidobacterium on pathogenic bacteria by reducing the $\mathrm{pH}$ of the intestinal environment. This was done by producing short chain volatile fatty acids, the use of nutrients, and the production of certain antimicrobial compounds, such as bacteriosins (26). In 2000, Saarela reported that Lactobacillus acidophilus (L. acidophilus) intercropping reduces the life of S. aureus, S. Flexneri, E. coli, Klebsiella pneumonia, B. cereus, P. aeruginosa, and Enterobacteriaceae strains in culture media. Antimicrobials with low molecular weight, which are independent of lactic acid production, have no effect on Lactobacillus or Bifidobacterium strains. The antimicrobial activity of this bacterium against Salmonella typhimurium (S. typhimurium) has also been shown in infected mice (27, 28). Conconnier et al. reported that the use of L. casei, L. acidophilus, and Lactobacillus lactis (L. lactis) supernatant culture has a bactericidal effect on the wide range of gram- 
positive and gram-negative pathogens. In the above studies, the highest inhibitory effect of L. plantarum is clear in the results on all three pathogens of Shigella dysentery, $S$. typhimurium, and E. coli (29). It has been shown that EHEC O157 produces a autoinducer-2 (AI-2) and it is used for bacterial interspecies relationships $(30,31)$. This molecule was first defined as a furanosyl borate diester (32); and it was later proved that the enzyme responsible for AI-2 synthesis was encoded by the luxS gene in EHEC O157 (33). In their 2007 study, Medellin et al. indicated that L. acidophilus has strategies that interfere with QS regulation of pathogens in foods such as E. coli O157, indicating that L. acidophilus reduces the production of AL-2 molecules by E. coli O157 (34); the reported results confirm the results of our study. In our study, native Lactobacillus was assessed using molecular technique and in the genetic level, unlike other studies that assessed the phenotypic view, and this was strong point of present study. It is recommended that other bacterial pathogenic agents involved in pathogenesis be studied in future studies.

\subsection{Conclusion}

L. casei and L. plantarum isolated from dairy products can reduce the expression of Stx 1 and Stx2 genes, which are a component of bacterial pathogenicity. Also, these two genes can be useful in controlling the infection caused by this bacterium.

\section{Acknowledgments}

We are grateful to the vice president of Science and technology unit at Ahar Azad University who helped us with this project.

\section{Footnotes}

Conflict of Interest: The authors declare that they have no conflict of interest.

Ethics Statement: The article did not conduct any studies on patients. Moreover, this article did not contain studies with human or animal subjects performed by any of the authors that needed to be approved by the ethics committee.

Funding/Support: This study was funded by Islamic Azad University, Ahar branch, IRAN. (2209508230017).

\section{References}

1. LeBlanc JG, Milani C, de Giori GS, Sesma F, van Sinderen D, Ventura M. Bacteria as vitamin suppliers to their host: a gut microbiota perspective. Curr Opin Biotechnol. 2013;24(2):160-8. doi: 10.1016/j.copbio.2012.08.005. [PubMed: 22940212].
2. Endt K, Stecher B, Chaffron S, Slack E, Tchitchek N, Benecke A, et al. The microbiota mediates pathogen clearance from the gut lumen after non-typhoidal Salmonella diarrhea. PLoS Pathog. 2010;6(9). e1001097. doi: 10.1371/journal.ppat.1001097. [PubMed: 20844578]. [PubMed Central: PMC2936549].

3. Collins SM, Surette M, Bercik P. The interplay between the intestinal microbiota and the brain. Nat Rev Microbiol. 2012;10(11):735-42. doi: 10.1038/nrmicro2876. [PubMed: 23000955].

4. Yu J, Feng Q, Wong SH, Zhang D, Liang QY, Qin Y, et al. Metagenomic analysis of faecal microbiome as a tool towards targeted noninvasive biomarkers for colorectal cancer. Gut. 2017;66(1):70-8. doi: 10.1136/gutjnl-2015-309800. [PubMed: 26408641].

5. Hill C, Guarner F, Reid G, Gibson GR, Merenstein DJ, Pot B, et al. Expert consensus document. The International Scientific Association for Probiotics and Prebiotics consensus statement on the scope and appropriate use of the term probiotic. Nat Rev Gastroenterol Hepatol. 2014;11(8):506-14. doi: 10.1038/nrgastro.2014.66. [PubMed: 24912386].

6. Vanderhoof JA, Mitmesser SH. Probiotics in the management of children with allergy and other disorders of intestinal inflammation Benef Microbes. 2010;1(4):351-6. doi: 10.3920/BM2010.0034. [PubMed 21831774].

7. Nixon AF, Cunningham SJ, Cohen HW, Crain EF. The effect of Lactobacillus GG on acute diarrheal illness in the pediatric emergency department. Pediatr Emerg Care. 2012;28(10):1048-51. doi: 10.1097/PEC.ob013e31826cad9f. [PubMed: 23023475]. [PubMed Central: PMC3760261].

8. Suzuki N, Mittler R. Reactive oxygen species-dependent wound responses in animals and plants. Free Radic Biol Med. 2012;53(12):226976. doi: 10.1016/j.freeradbiomed.2012.10.538. [PubMed: 23085520].

9. Franken L, Schiwon M, Kurts C. Macrophages: sentinels and regulators of the immune system. Cell Microbiol. 2016;18(4):475-87. doi: 10.1111/cmi.12580. [PubMed: 26880038].

10. Lebeer S, Vanderleyden J, De Keersmaecker SC. Host interactions of probiotic bacterial surface molecules: comparison with commensals and pathogens. Nat Rev Microbiol. 2010;8(3):171-84. doi: 10.1038/nrmicro2297. [PubMed: 20157338].

11. Tarr PI, Grodon CA, Chandler WL. Shiga toxin producing Escherichia coli and hemolytic uremic syndrom. Lancet. 2005;41(219-26).

12. Takahashi M, Taguchi H, Yamaguchi H, Osaki T, Komatsu A, Kamiya S. The effect of probiotic treatment with Clostridium butyricum on enterohemorrhagic Escherichia coli O157:H7 infection in mice. FEMS Immunol Med Microbiol. 2004;41(3):219-26. doi: 10.1016/j.femsim.2004.03.010. [PubMed: 15196571].

13. Pamela HR, Davis KC, Garstka WR, Bhunia AK. Lactat dehydrogenase realase assay from vero cells to distinguish verotoxin producing Escherichia coli from non-Vero toxin produc- ing strains. J Microbiol Methods. 2000;43:171-8.

14. Whelan K. Probiotics and prebiotics in the management of irritable bowel syndrome: a review of recent clinical trials and systematic reviews. Curr Opin Clin Nutr Metab Care. 2011;14(6):581-7. doi: 10.1097/MCO.0b013e32834b8082. [PubMed: 21892075].

15. Kaper JB, Nataro JP, Mobley HL. Pathogenic Escherichia coli. Nat Rev Microbiol. 2004;2(2):123-40. doi: 10.1038/nrmicro818. [PubMed: 15040260].

16. Momose Y, Hirayama K, Itoh K. Effect of organic acids on inhibition of Escherichia coli $0157: \mathrm{H} 7$ colonization in gnotobiotic mice associated with infant intestinal microbiota. Antonie Van Leeuwenhoek. 2008;93(1-2):141-9. doi: 10.1007/s10482-007-9188-9. [PubMed: 17674138].

17. Rasko DA, Webster DR, Sahl JW, Bashir A, Boisen N, Scheutz F, et al. Origins of the E. coli strain causing an outbreak of hemolytic-uremic syndrome in Germany. N Engl J Med. 2011;365(8):709-17. doi: 10.1056/NEJMoa1106920. [PubMed: 21793740]. [PubMed Central: PMC3168948].

18. Hughes AK, Stricklett PK, Schmid D, Kohan DE. Cytotoxic effect of Shiga toxin-1 on human glomerular epithelial cells. Kidney Int 2000;57(6):2350-9. doi: 10.1046/j.1523-1755.2000.00095.x. [PubMed 10844605] 
19. Hughes AK, Stricklett PK, Kohan DE. Cytotoxic effect of Shiga toxin1 on human proximal tubule cells. Kidney Int. 1998;54(2):426-37. doi 10.1046/j.1523-1755.1998.00015.x. [PubMed: 9690209].

20. Obrig TG, Louise CB, Lingwood CA, Boyd B, Barley-Maloney L, Daniel TO. Endothelial heterogeneity in Shiga toxin receptors and responses. J Biol Chem. 1993;268(21):15484-8. [PubMed: 8340376].

21. Silva M, Jacobus NV, Deneke C, Gorbach SL. Antimicrobial substance from a human Lactobacillus strain. Antimicrob Agents Chemother. 1987;31(8):1231-3. doi: 10.1128/AAC.31.8.1231. [PubMed: 3307619]. [PubMed Central: PMC174909].

22. Qin H, Zhang Z, Hang X, Jiang Y. L. plantarum prevents enteroinvasive Escherichia coli-induced tight junction proteins changes in intestinal epithelial cells. BMC Microbiol. 2009;9:63. doi: 10.1186/1471-2180-963. [PubMed: 19331693]. [PubMed Central: PMC2674056].

23. Ogunbanwo ST, Sanni AI, Onilude AA. Characterization of bacteriocin produced by Lactobacillus plantarum F1 and Lactobacillus brevis OG1. African Journal of Biotechnology. 2003;2(8):219-27. doi: 10.5897/ajb2003.000-1045.

24. Wolf L, Erickson KL, Hubbard N. Bacteriocins of lactic acid bacteria Journal Nutr. 2000;130(2):403-9.

25. Lee YK, Puong KY, Ouwehand AC, Salminen S. Displacement of bacterial pathogens from mucus and Caco-2 cell surface by lactobacilli. J Med Microbiol. 2003;52(Pt 10):925-30. doi: 10.1099/jmm.0.05009-0. [PubMed: 12972590].

26. Fooks LJ, Gibson GR. Mixed culture fermentation studies on the effects of synbiotics on the human intestinal pathogens Campylobacter jejuni and Escherichia coli. Anaerobe. 2003;9(5):231-42. doi 10.1016/S1075-9964(03)00043-X. [PubMed: 16887709].

27. Saarela M, Mogensen G, Fonden R, Matto J, Mattila-Sandholm T. Probiotic bacteria: safety, functional and technological properties. J Biotechnol. 2000;84(3):197-215. doi: 10.1016/S0168-1656(00)00375-8.
[PubMed: 11164262].

28. Hudault S, Lievin V, Bernet-Camard MF, Servin AL. Antagonistic activity exerted in vitro and in vivo by Lactobacillus casei (strain GG) against Salmonella typhimurium C5 infection. Appl Environ Microbiol. 1997;63(2):513-8. [PubMed: 9023930]. [PubMed Central: PMC168342].

29. Coconnier MH, Lievin V, Hemery E, Servin AL. Antagonistic activity against Helicobacter infection in vitro and in vivo by the human Lactobacillus acidophilus strain LB. Appl Environ Microbiol. 1998;64(11):4573-80. [PubMed: 9797324]. [PubMed Central: PMC106686].

30. Schauder S, Shokat K, Surette MG, Bassler BL. The LuxS family of bacterial autoinducers: biosynthesis of a novel quorum-sensing signal molecule. Mol Microbiol. 2001;41(2):463-76. doi: 10.1046/j.13652958.2001.02532.x. [PubMed: 11489131]

31. Sperandio V, Torres AG, Giron JA, Kaper JB. Quorum sensing is a global regulatory mechanism in enterohemorrhagic Escherichia coli O157:H7. J Bacteriol. 2001;183(17):5187-97. doi: 10.1128/JB.183.17.51875197.2001. [PubMed: 11489873]. [PubMed Central: PMC95396].

32. Chen X, Schauder S, Potier N, Van Dorsselaer A, Pelczer I, Bassler BL, et al. Structural identification of a bacterial quorum-sensing signal containing boron. Nature. 2002;415(6871):545-9. doi: 10.1038/415545a. [PubMed: 11823863].

33. Surette MG, Miller MB, Bassler BL. Quorum sensing in Escherichia coli, Salmonella typhimurium, and Vibrio harveyi: a new family of genes responsible for autoinducer production. Proc Natl Acad SciUSA. 1999;96(4):1639-44. doi: 10.1073/pnas.96.4.1639. [PubMed: 9990077]. [PubMed Central: PMC15544].

34. Medellin-Pena MJ, Griffiths MW. Effect of molecules secreted by Lactobacillus acidophilus strain La-5 on Escherichia coli O157:H7 colonization.Appl Environ Microbiol.2009;75(4):1165-72. doi:10.1128/AEM.0165108. [PubMed:19088323]. [PubMed Central: PMC2643578]. 